Article

\title{
The Biological Properties and Potential Interacting Proteins of D-Alanyl-D-alanine Ligase A from Mycobacterium tuberculosis
}

\author{
Shufeng Yang, Yuefei Xu, Yan Wang, Feng Ren, Sheng Li, Wenyong Ding, Yufang Ma * \\ and Wenli Zhang * \\ Department of Biochemistry and Molecular Biology, Dalian Medical University, Dalian 116044, China; \\ shufengyang78@163.com (S.Y.); xuyf0051@163.com (Y.X.); yanwang_2018@163.com (Y.W.); \\ renfeng16@163.com (F.R.); lisheng_1996@163.com (S.L.); dingwy@dlmedu.edu.cn (W.D.) \\ * Correspondence: yufang_ma@hotmail.com (Y.M.); zhangwenliyf@hotmail.com (W.Z.)
}

Received: 21 December 2017; Accepted: 1 February 2018; Published: 3 February 2018

\begin{abstract}
Background: D-alanine-D-alanine ligase (DdlA), an effective target for drug development to combat against Mycobacterium tuberculosis (Mtb), which threatens human health globally, supplies a substrate of D-alanyl-D-alanine for peptidoglycan crosslinking by catalyzing the dimerization of two D-alanines. To obtain a better understanding of DdlA profiles and develop a colorimetric assay for high-throughput inhibitor screening, we focused on explicating and characterizing Tb-DdlA. (2) Methods and Results: Rv2981c (ddlA) was expressed in Escherichia coli, and the purified Tb-DdlA was identified using (anti)-polyhistidine antibody followed by DdlA activity confirmation by measuring the released orthophosphate via colorimetric assay and the yielded D-alanyl-D-alanine through high performance thin layer chromatography (HP-TLC). The kinetic assays on Tb-DdlA indicated that $T b$-DdlA exhibited a higher affinity to ATP $\left(\mathrm{K}_{\mathrm{mATP}}\right.$ : $\left.50.327 \pm 4.652 \mu \mathrm{mol} / \mathrm{L}\right)$ than alanine $\left(\mathrm{K}_{\mathrm{mAla}}\right.$ : $1.011 \pm 0.094 \mathrm{mmol} / \mathrm{L})$. A colorimetric assay for Tb-DdlA activity was developed for high-throughput screening of DdlA inhibitors in this study. In addition, we presented an analysis on $T b$-DdlA interaction partners by pull-down assay and MS/MS. Eight putative interaction partners of $T b$-DdlA were identified. (3) Conclusions: Our dataset provided a valuable resource for exploring $T b$-DdlA biology, and developed an easy colorimetric assay for screening of $T b$-DdlA inhibitors.
\end{abstract}

Keywords: Mycobacterium; D-alanine-D-alanine ligase; peptidoglycan

\section{Introduction}

According to the 2017 statistic report by the WHO [1], Tuberculosis (TB) killed approximately 1.4 million people worldwide in 2016 and an estimated 10.4 million new TB cases occurred annually. The current anti-TB treatment regimens, in particular, remain very unsatisfactory for infection with Mycobacterium tuberculosis ( $M t b$ ) strains of MDR (multidrug-resistance) or XDR (extensively drug-resistance) [1]. $M t b$, a causative pathogen of TB [1-3], has been found to be the dominant strain with MDR or XDR at present. So far, intensive worldwide efforts have been made to discover novel anti-TB drug targets or innovative anti-TB drugs to combat against these evolved $M t b$ strains.

The DdlA (D-alanyl-D-alanine ligase A) in Mtb, catalyzing the dimerization of two D-alanine molecules, has been of particular interest as a potential and attractive anti-TB drug target [4-6]. The ATP-dependent dimerization reactions catalyzed by DdlA proceed through the phosphorylation of the D-alanine at the carboxyl group by the $\gamma$-phosphate of ATP to produce an acylphosphate intermediate firstly. Then, a tetrahedral intermediate is formed by the nucleophilic attacking of the amino nitrogen of the second D-alanine on the acylphosphate intermediate. Finally, a phosphate 
group is released from the tetrahedral intermediate to generate the final product of D-alanyl-D-alanine (Figure 1) [7-9].

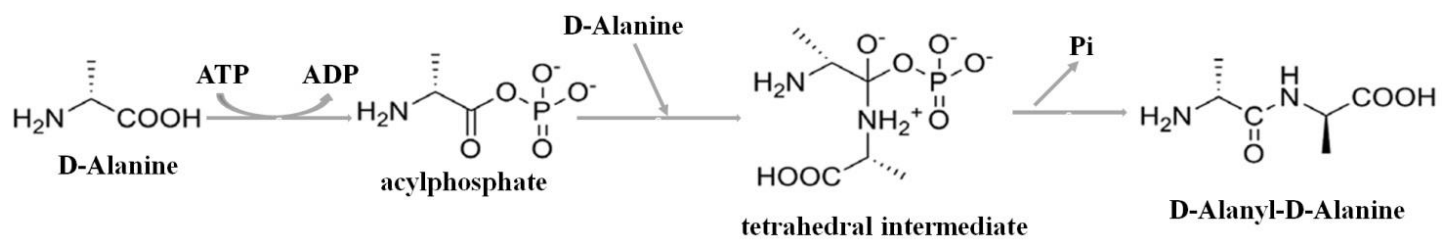

Figure 1. A series of chemical reactions catalyzed by DdlA.

D-alanyl-D-alanine is involved in the pentapeptide biosynthesis of peptidoglycan (PG) as a dipeptide donor. PG is a universal and pivotal component of the mycobacterial cell wall. It is fundamental for bacteria to maintain the defined cell morphology, withstand the internal osmotic pressure, and affect cell division [10-13]. The biosynthesis of PG is an ideal target for anti-TB drug design because the whole pathways are not present in mammalian cells [9]. DdlA is one of the potent candidates as an anti-TB drug target among a great deal of factors that affect PG biosynthesis because (1) it utilizes D-alanine as its substrate, which is specific for bacterial PG biosynthesis; (2) it is essential in mycobacteria, and its essentiality was confirmed by means of transposon mutagenesis in 2003; and (3) the product of DdlA catalyzed reaction is D-ananly-D-alanine which promotes the cross-linking of PG by synthesizing the integrated pentapeptide. DdlA is responsible for supplying a substrate of D-alanyl-D-alanine for PG crosslinking.

D-cycloserine (DCS), a cyclic analogue of D-alanine and an effective second-line antibiotic against $M t b$, inhibits the biosynthesis of the bacterial cell wall by targeting alanine racemase (Alr) and D-alanine:D-alanine ligase (Ddl). Nowadays, DCS is restricted to TB treatment due to its neurological side effects. DCS can be hydrolyzed to generate D-serine, which is a potent agonist at the glycine site of the NMDAR ( $N$-methyl-D-aspartate-type glutamate receptor) which causes central nervous system side effects, such as headaches, drowsiness, depression, dizziness, vertigo, confusion, paresthesias, dysarthria, hyperirritability, psychosis, convulsions, and tremors. Overdose of DCS may result in paresis, seizures, and coma $[6,14,15]$.

Nevertherless, $T b$-DdlA is of particular importance as an effective and attractive anti-TB drug target. To obtain a better understanding of the DdlA profiles and develop a colorimetric assay for high-throughput inhibitor screening, we focused on explicating and characterizing Tb-DdlA which serves as a non-toxic and effective anti-TB compound screening.

\section{Results}

\subsection{The Detection of Soluble Tb-DdlA Protein Expressed in Escherichia coli}

The $T b$ - $d d l A$ gene was cloned into the HindIII and NdeI sites of pColdII generating a Tb-DdlA fusion protein with an N-terminal histidine tag (His-tag), which serves as a selective and efficient tool for protein purification and detection. The expected molecular weight of the $T b$-DdlA fusion protein was about $39.68 \mathrm{kDa}$ of $\mathrm{Tb}$-DdlA protein, plus $1 \mathrm{kDa}$ of the His-tag. The expressed protein was purified by $\mathrm{Ni}^{2+}$-NTA affinity chromatography from supernatant of cell lysates, and was examined using polyacrylamide gel electrophoresis (PAGE) and Western blot. The PAGE and Western blot results displayed that only one band was visible on the gel and nitrocellulose membrane for the purified $T b$-DdlA fusion protein, which had a molecular weight around $40 \mathrm{kDa}$, which was consistent with the expected size of $T b$-DdlA fusion protein (about $40 \mathrm{kDa}$ ) (Figure 2A,B). Figure 2C,D shows that the monoclonal anti-polyhistidine antibody, which was used to blot the expressed $T b$-DdlA, was specific for the expressed $T b$-DdlA fusion protein with His-tag compared to its negative control. Therefore, the PAGE and Western blot analysis demonstrated that a soluble Tb-DdlA protein was successfully and highly-efficiently expressed as a fusion protein with histidine tag in E. coli BL21(DE3). 


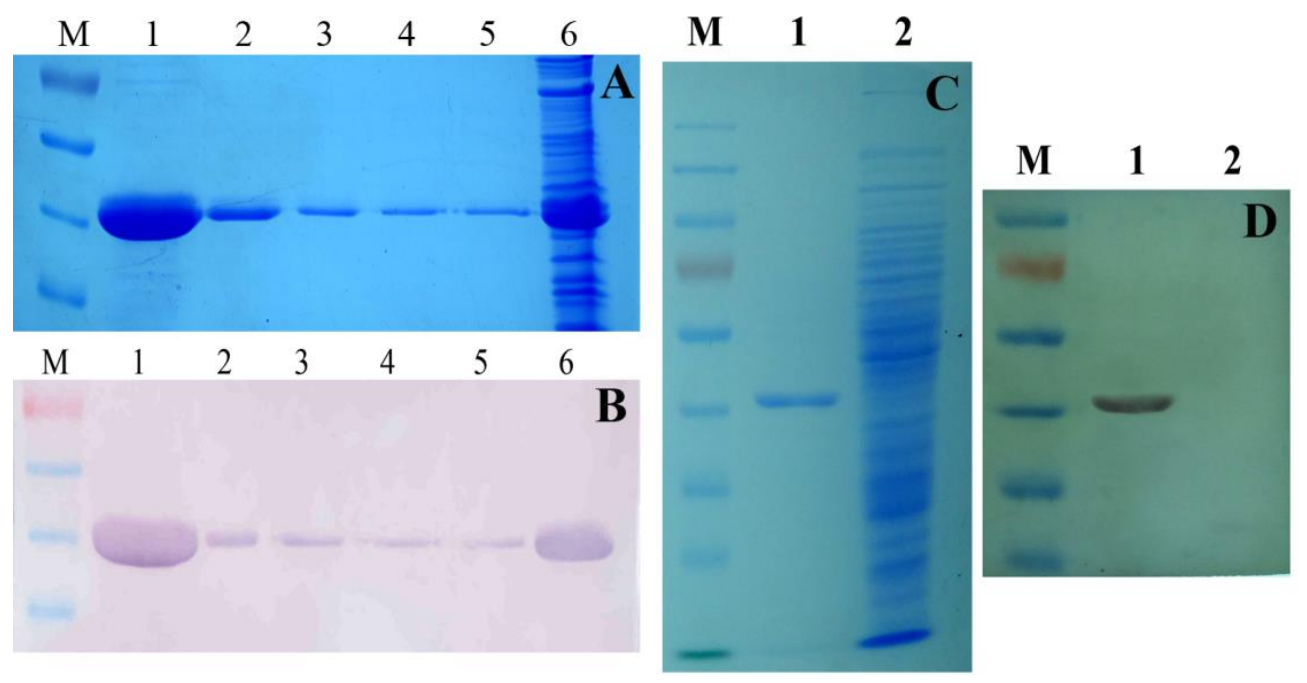

Figure 2. Analysis of the purified Tb-DdlA fusion protein by PAGE and Western blot. M, PageRuler prestained protein ladder (Fermentas), the sizes of the bands from top to bottom were $180 \mathrm{kDa}, 130 \mathrm{kDa}$, $100 \mathrm{kDa}, 70 \mathrm{kDa}$ (red), $55 \mathrm{kDa}, 40 \mathrm{kDa}, 35 \mathrm{kDa}, 25 \mathrm{kDa}$, and $15 \mathrm{kDa}$, respectively. (A) PAGE analysis of $T b$-DdlA; $1-5$, the elute fraction of $T b$-DdlA fusion protein (with histidine tag) with an expected molecular weight of around $40 \mathrm{kDa}$ purified by $\mathrm{Ni}^{2+}$-NTA affinity chromatography; 6 , cell lysate from E. coli BL21(DE3) harboring pCold-ddlA; (B) Western Blot analysis of Tb-DdlA. The monoclonal anti-polyhistidine antibody at 1 to 5000 dilution was used to blot the expressed Tb-DdlA. The bands on the gel were visualized by BCIP/NBT solution; $1-5$, the elute fraction of the Tb-DdlA fusion protein (with the histidine tag) with an expected molecular weight of around $40 \mathrm{kDa}$ purified by $\mathrm{Ni}^{2+}$-NTA affinity chromatography; 6 , cell lysate from E. coli BL21(DE3) harboring pCold-ddlA; (C) PAGE analysis of purified $T b$-DdlA; 1, purified $T b$-DdlA; 2, cell lysate from $E$. coli BL21(DE3) harboring pColdII; (D) Western Blot analysis of Tb-DdlA. The monoclonal anti-polyhistidine antibody at a 1 to 5000 dilution was used to blot the expressed $T b$-DdlA. The bands on the gel were visualized by BCIP/NBT solution; 1, purified Tb-DdlA; 2, cell lysate from E. coli BL21(DE3) harboring pColdII.

\subsection{The Profiles of Tb-DdlA D-Alanyl-D-alanine Ligase Activity}

\subsubsection{Confirmation of DdlA Activity}

The DdlA that catalyzes the dimerization of two D-alanine molecules typically couples ATP hydrolysis to provide a thermodynamic driving force and exhibits a cleavage of ATP to ADP and orthophosphate. Thus, in this study, the colorimetric assay demonstrated D-alanyl-D-alanine ligase activity of DdlA as evidence from orthophosphate released, which was measured by adding malachite green reagent. Table 1 showed a high D-alanyl-D-alanine ligase activity of DdlA. Thus, the coupled colorimetric assay demonstrated that $T b$-DdlA encoded by Rv2981c possessed ligase activity toward D-alanine by liberating a molecule of orthophosphate. In addition, the D-alanyl-D-alanine ligase activity was confirmed by detecting the yielded D-Alanyl-D-alanine using HP-TLC. The HP-TLC was performed in the solvent system of phenol:water (4:1), and the color spots were visualized by spraying $2 \%$ ninhydrin solution. The HP-TLC image displays the band of D-alanyl-D-alanine formed by dimerization of two molecules of D-alanine (Figure 3). The D-alanine was completely converted into D-alanyl-D-alanine, so no remaining D-alanine was detected on the plate. The reaction mixture containing all reactants, except $T b$-DdlA, was used as a negative control in this study. Therefore, the coupled colorimetric assay and HP-TLC image confirmed that Tb-DdlA encoded by Rv2981c possessed ligase activity toward D-alanine to generate a dipeptide of D-alanyl-D-alanine with liberation of a molecule of orthophosphate. 
Table 1. The assay of D-alanyl-D-alanine ligase activity on Tb-DdlA. The decreasing D-alanine in the reaction mixture was measured by colorimetric reaction coupled with malachite green reagents. The analysis was conducted in quadruplicate.

\begin{tabular}{|c|c|c|c|c|c|}
\hline Reactions & \multicolumn{2}{|c|}{ Components } & Mean Values of & Net Mean \pm SD & Z-Factor \\
\hline \multirow{2}{*}{ Reaction 1} & $\begin{array}{l}100 \text { mmol/L ATP; } \\
2 \mathrm{mmol} / \mathrm{L} \mathrm{D}-\mathrm{Ala}\end{array}$ & $20 \mu \mathrm{g} / \mathrm{mL}$ DdlA & $0.692 \pm 0.099$ & \multirow{2}{*}{$0.452 \pm 0.099$} & 0.187 \\
\hline & $\begin{array}{l}100 \mu \mathrm{mol} / \mathrm{L} \mathrm{ATP} ; \\
2 \mathrm{mmol} / \mathrm{L} \mathrm{D}-\mathrm{Ala}\end{array}$ & No DdlA & $0.240 \pm 0.023$ & & \\
\hline \multirow{2}{*}{ Reaction 2} & $\begin{array}{l}75 \mu \mathrm{mol} / \mathrm{L} \text { ATP; } \\
2 \mathrm{mmol} / \mathrm{L} \mathrm{D}-\mathrm{Ala}\end{array}$ & $10 \mu \mathrm{g} / \mathrm{mL}$ DdlA & $0.459 \pm 0.013$ & \multirow{2}{*}{$0.291 \pm 0.013$} & 0.735 \\
\hline & $\begin{array}{l}75 \mu \mathrm{mol} / \mathrm{L} \text { ATP; } \\
2 \mathrm{mmol} / \mathrm{L} \mathrm{D}-\mathrm{Ala}\end{array}$ & No DdlA & $0.168 \pm 0.013$ & & \\
\hline
\end{tabular}

The above values in net mean \pm SD had been deducted from values in DdlA group minus ones in its control group.

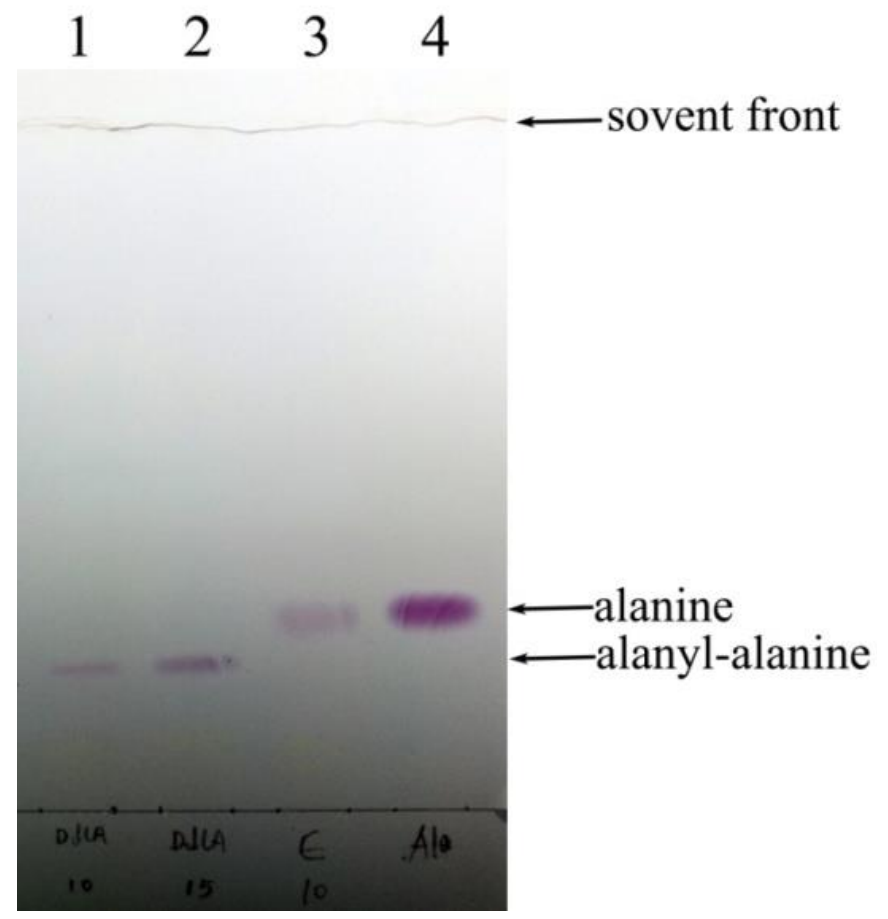

Figure 3. The identification of D-alanyl-D-alanine ligase activity of Tb-DdlA by HP-TLC. Phenol:water of 4:1 was used as the developing reagent. The color spots were visualized by spraying ninhydrin; 4, the standard D-alanine; 3, control, no DdlA in the reaction mixture; 2, reactant, D-alanine was incubated with DdlA protein purified by $\mathrm{Ni}^{2+}$-NTA affinity choromatography; $15 \mu \mathrm{L}$ was loaded; 1 , reactant, D-alanine was incubated with DdlA protein purified by $\mathrm{Ni}^{2+}-\mathrm{NTA}$ affinity choromatography; $10 \mu \mathrm{L}$ was loaded.

In addition, the Z-factor, a measure of the statistical effect size which has been proposed for use in high-throughput screening, was estimated according to the following equation: Z-factor $=1-3\left(\sigma_{p}+\right.$ $\left.\sigma_{\mathrm{n}}\right) /\left|\mu_{\mathrm{p}}-\mu_{\mathrm{n}}\right|$ (parameters: $\mu$, means; $\sigma$, standard deviation; $\mathrm{p}$, positive of sample; $\mathrm{n}$, negative control of sample). The Table 1 showed that the Z-factor of Reaction 2 was 0.735 , which ranged between 0.5 and 1 , so it was more reliable for high-throughput screening compared to Reaction 1, whose Z-factor was 0.187 . 


\subsubsection{Kinetic Analysis of $T b$-DdlA}

The kinetic parameters of $T b$-DdlA were measured using a malachite green reagent-coupled assay. The catalytic activity of $T b$-DdlA was measured by varying D-alanine concentration, DdlA concentration, ATP concentration, and $\mathrm{pH}$ value in the reaction mixture, respectively, and incubation time and temperature, as well. Tb-DdlA was observed to display a higher D-alanyl-D-alanine ligase activity at more than $1 \mathrm{mmol} / \mathrm{L}$ of alanine concentration, more than $0.6 \mu \mathrm{g} / \mathrm{mL}$ of DdlA concentration, $50 \mu \mathrm{mol} / \mathrm{L}$ of ATP concentration, $\mathrm{pH} 8.0$, and cultivating at $37^{\circ} \mathrm{C}$ for more than $30 \mathrm{~min}$ (Figure 4). Therefore, an optimal enzymatic activity was determined according to the kinetic parameters and Z-factor as follows: $2 \mathrm{mmol} / \mathrm{L}$ alanine, $10 \mu \mathrm{g} / \mathrm{mL}$ DdlA, $75 \mu \mathrm{mol} / \mathrm{L}$ of ATP, and cultivating at $37{ }^{\circ} \mathrm{C}$ in the $\mathrm{pH} 8.0$ reaction mixture for $60 \mathrm{~min}$. In addition, the $\mathrm{K}_{\mathrm{m}}, \mathrm{V}_{\max }$, and $\mathrm{K}_{\text {cat }}$ values of the $T b$-DdlA for the substrate of D-alanine and ATP were determined by a double-reciprocal plot under the optimal catalytic conditions. The $\mathrm{K}_{\mathrm{mATP}}$ was $50.327 \pm 4.652 \mu \mathrm{mol} / \mathrm{L}$ and the $\mathrm{V}_{\mathrm{mATP}}$ was $204.082 \pm 1.021 \mathrm{mmol} / \mathrm{min} / \mathrm{mg}$ at $\mathrm{pH} 8.0$ and $37^{\circ} \mathrm{C}$ (Figure $4 \mathrm{H}$ ); $\mathrm{K}_{\mathrm{mAla}}$ was $1.011 \pm 0.094 \mathrm{mmol} / \mathrm{L}$ and $\mathrm{V}_{\mathrm{mAla}}$ was $71.942 \pm 0.884 \mathrm{mmol} / \mathrm{min} / \mathrm{mg}$ under the above optimal conditions of enzyme-catalyzed chemical reaction (Figure $4 \mathrm{H}$ ). $\mathrm{K}_{\text {cat }}$ was $0.044 \pm 0.002 \mathrm{~min}^{-1}$. Therefore, the double-reciprocal plot indicated that the enzyme exhibited a higher affinity to ATP than D-alanine.
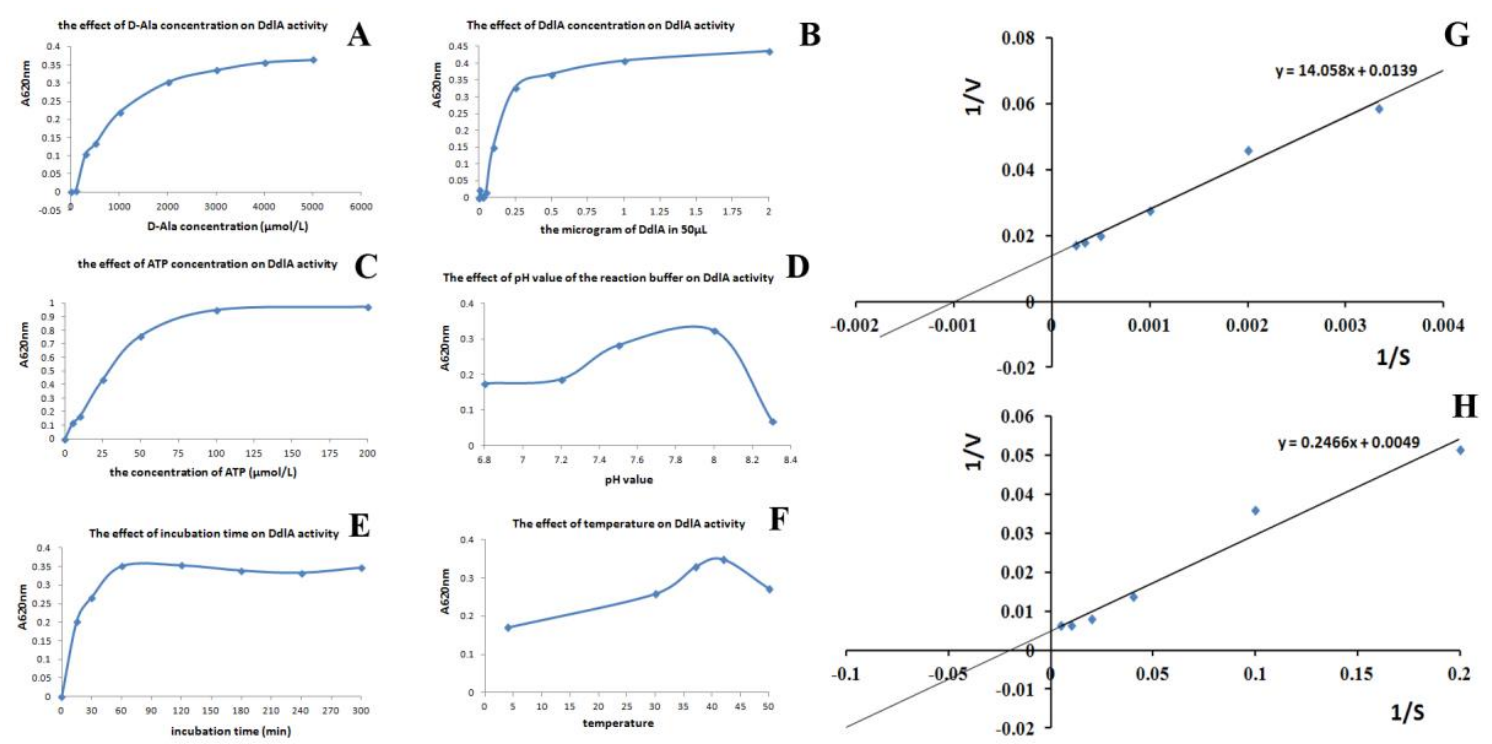

Figure 4. Determination of optimal reaction conditions for $M t b$ DdlA activity assay. (A-F) represented the effect of alanine concentration, DdlA concentration, ATP concentration, $\mathrm{pH}$, incubation time, and temperature on the enzyme activity respectively; $(\mathbf{G})$ The effect of alanine concentration on Tb-DdlA activity analyzed by the double reciprocal plot; $(\mathbf{H})$ The effect of ATP concentration on Tb-DdlA activity analyzed by the double reciprocal plot.

\subsubsection{Inhibitory Analysis of Tb-DdlA Using DCS}

To demonstrate whether the colorimetric assay to measure the released orthophosphate using malachite green reagent can be utilized for screening of $T b$-DdlA's inhibitory compounds, the DCS, a known competitive inhibitor typically with close structural similarities to D-alanine, was used as a positive control in this study. Double-reciprocal plots for the mode of $T b$-DdlA inhibition by DCS with respect to the substrate of D-alanine were demonstrated herein. The concentrations of inhibitors including $0,25,50,100,200,300 \mu \mathrm{g} / \mathrm{mL}$ were used in this study. However, only a high concentration of DCS ( $\geq 200 \mu \mathrm{g} / \mathrm{mL}(1.959 \mathrm{mmol} / \mathrm{L})$ ) exhibited an obviously inhibitory effect on Tb-DdlA (Figure 5), and the inhibitory effect enhanced as the concentration of DCS increased. 


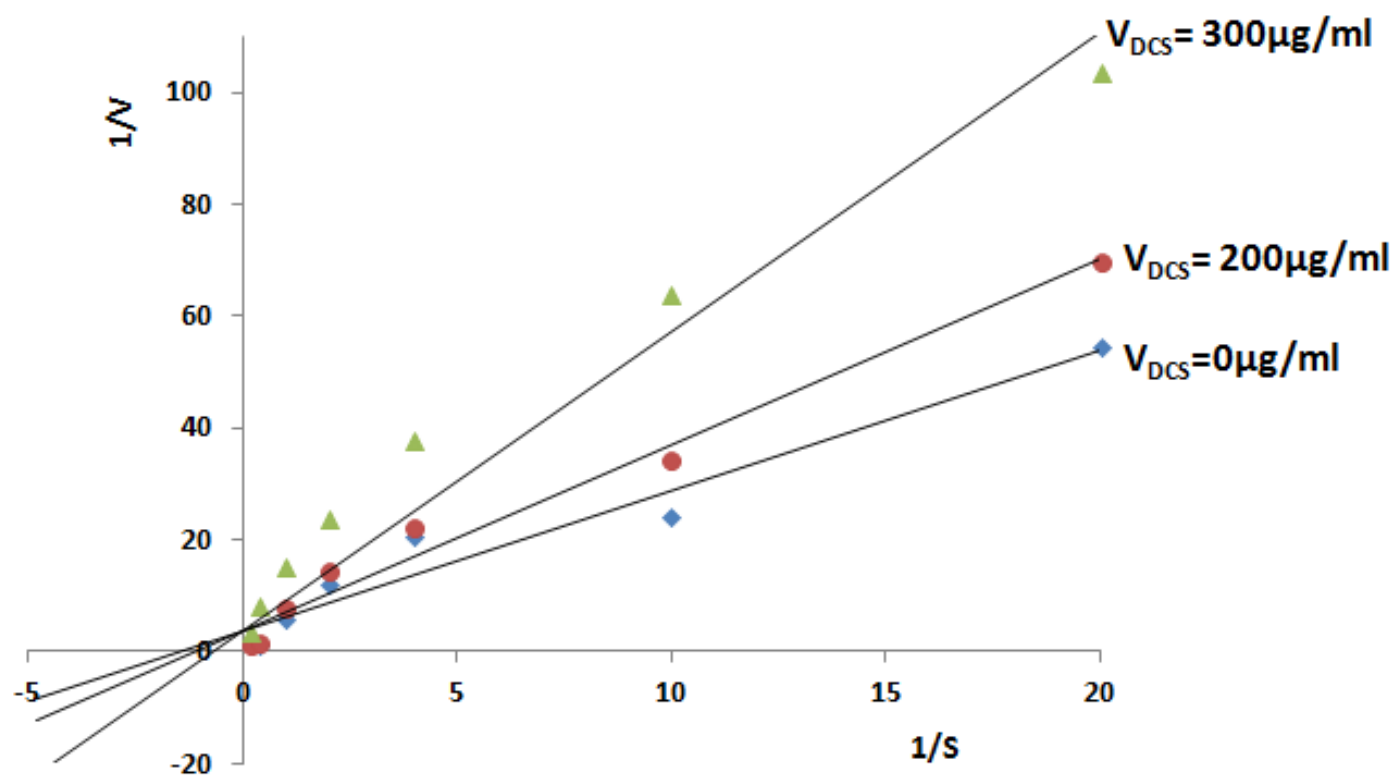

Figure 5. Steady state inhibition by DCS on D-alanyl-D-alanine ligase activity of DdlA. The double-reciprocal plots were obtained without or with different concentrations of DCS. The Lineweaver-Burk plot analysis of the data also confirmed the competitive inhibition.

\subsection{The Identification of $\mathrm{Tb}-\mathrm{D} d l \mathrm{~A}$ Potential Interaction Partners}

Identifying interaction partners is key to understanding the function of a protein. In this study, the pull-down assay was used to obtain proteins in Msm that complexed with Tb-DdlA using $T b$-DdlA-coated magnetic beads. To establish the pull-down assay, we expressed $T b$-DdlA as a recombinant $\mathrm{His}_{6}$-fusion protein in E. coli and purified it to homogeneity. The loaded Tb-DdlA fusion protein was covalently coupled to $\mathrm{Ni}^{2+}$-NTA-activated sepharose beads, which were used to pull down putative interacting proteins from cell lysates of $\mathrm{Msm}$. After washing, the putative interacting proteins were eluted and analyzed by PAGE and silver staining. In total, four extra bands were obtained by pull-down techniques (Figure 6).

The proteins from four bands on PAGE were deciphered as putative interaction partners of $T b$-DdlA by mass spectrometry. The MS/MS analysis resulted in identification of eight different potential interacting partners of $T b$-DdlA in total (Table 2). The list contained two well-known interactors which were involved in protein expression, including LuxR family transcriptional regulator (cupin) and elongation factor Tu (Tuf). The remaining five putative interacting partners were FAD-dependent oxidoreductase, ornithine-oxo-acid transaminase, diaminopimelate decarboxylase, cyclopropane-fatty-acyl-phospholipid synthase, and carbon-monoxide dehydrogenase large subunit, respectively. The last one was the hypothetical protein LI98_12890. 


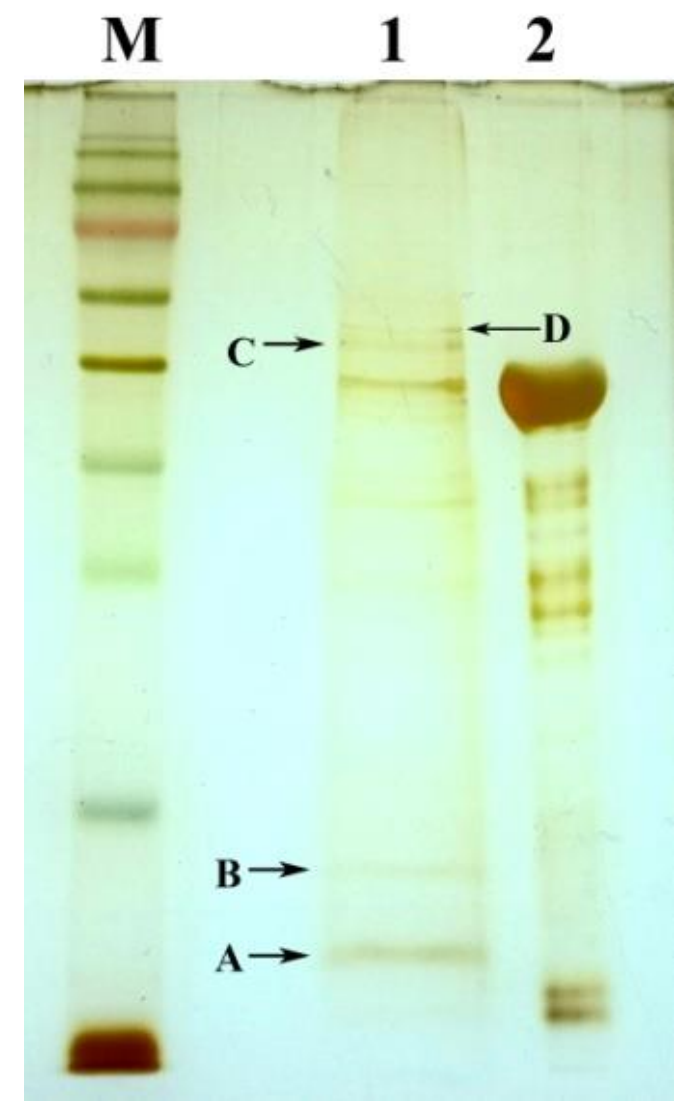

Figure 6. The PAGE analysis on Tb-DdlA interaction partners obtained by pull-down assay. The gel was stained by silver staining. M, PageRuler prestained protein ladder (Fermentas), the band sizes from top to bottom are $180 \mathrm{kDa}, 130 \mathrm{kDa}, 100 \mathrm{kDa}, 70 \mathrm{kDa}$ (red), $55 \mathrm{kDa}, 40 \mathrm{kDa}, 35 \mathrm{kDa}, 25 \mathrm{kDa}, 15 \mathrm{kDa}$, and 10 $\mathrm{kDa}$, respectively; $\mathbf{1}, \mathrm{T} b$-DdlA interaction protein complexes obtained by pull-down assay; $2, T b$-DdlA purified by $\mathrm{Ni}^{2+}$-NTA affinity chromatography. A-D, the bands selected for MS identification. 
Table 2. The list of the putative interaction partners of Tb-DdlA in Msm detected by MS/MS. A, B, C and D were the corresponding bands from the silver-stained polyacrylamide gel.

\begin{tabular}{|c|c|c|c|c|c|c|c|c|}
\hline ID & Protein Name & $\begin{array}{l}\text { Accession No. } \\
\text { (NCBI) }\end{array}$ & $\begin{array}{l}\text { Locus Name/Gene } \\
\text { Definition }\end{array}$ & $\begin{array}{l}\text { Protein MW } \\
\text { (D) }\end{array}$ & Protein PI & Pep. Count & $\begin{array}{c}\text { Protein } \\
\text { Score }\end{array}$ & $\begin{array}{l}\text { Protein Score } \\
\text { C. I. } \%\end{array}$ \\
\hline $\mathrm{A}$ & $\begin{array}{l}\text { LuxR family transcriptional } \\
\text { regulator }\end{array}$ & AIU17347.1 & MSMEG_5707, cupin & $12,011.3$ & 6.36 & 5 & 285 & 100 \\
\hline B & hypothetical protein LI98_12890 & AIU21016.1 & MSMEG_2589 & $15,412.9$ & 6.28 & 7 & 314 & 100 \\
\hline \multirow{3}{*}{$\mathrm{C}$} & elongation factor $\mathrm{Tu}$ & YP_885786.1 & MSMEG_1401, tuf & $43,708.6$ & 5.18 & 18 & 696 & 100 \\
\hline & FAD-dependent oxidoreductase & AIU20161.1 & MSMEG_1682, FMO & $46,185.2$ & 5.86 & 13 & 74 & 99.697 \\
\hline & ornithine-oxo-acid transaminase & WP_011727654.1 & MSMEG_1413, rocD & $44,661.1$ & 5.62 & 14 & 72 & 99.581 \\
\hline \multirow{3}{*}{$\mathrm{D}$} & diaminopimelate decarboxylase & YP_889210.1 & MSMEG_4958, lysA & 50,317 & 5.25 & 13 & 224 & 100 \\
\hline & $\begin{array}{l}\text { cyclopropane-fatty-acyl-phospholipid } \\
\text { synthase }\end{array}$ & YP_890503.1 & MSMEG_6284 & $48,608.7$ & 5.99 & 13 & 198 & 100 \\
\hline & $\begin{array}{c}\text { carbon-monoxide dehydrogenase } \\
\text { large subunit }\end{array}$ & WP_011727162.1 & MSMEG_0746 & 85,807 & 5.21 & 19 & 60 & 93.366 \\
\hline
\end{tabular}




\section{Discussion}

The DdlA, an essential gene product determined by Himar1-based transposon mutagenesis in H37Rv strain [16], can dimerize two D-alanine molecules to generate the dipeptide of D-alanyl-D-alanine, which can be utilized as a substrate for PG biosynthesis and maturation. Tb-DdlA is of particular importance as an effective and attractive anti-TB drug target. In this study, we successfully expressed and purified soluble $T b$-DdlA and analyzed its enzymatic characteristics. In addition, according to the kinetic parameters of the enzyme, we developed a colorimetric assay to measure the released orthophosphate for high-throughput screening of $T b$-DdlA inhibitory compounds. During enzyme activity test, some disadvantages were found: (1) the color compound formed by malachite green reagent and orthophosphate had low solubility, so that an insoluble precipate was generated in the reaction mixture when it was catalyzed by Tb-DdlA with high activity. According to this property, we optimized the enzymatic parameters and Z-factor as follows: $2 \mathrm{mmol} / \mathrm{L}$ alanine, $10 \mu \mathrm{g} / \mathrm{mL}$ DdlA, $75 \mu \mathrm{mol} / \mathrm{L}$ of ATP in the $\mathrm{pH} 8.0$ reaction mixture at $37^{\circ} \mathrm{C}$ for $60 \mathrm{~min}$. (2) malachite green reagent easily turned green in color even without adding anything, so we needed to perform color developing carefully in case the malachite green reagent was contaminated. Most importantly, the colorimetric assay to measure the released orthophosphate allowed a fast and accurate determination of $T b$-DdlA's ligase activity. Actually, in order to overcome the disadvantage of enzyme activty determination by adding malachite green reagent, we introduced a colorimetric assay of $T b$-DdlA activity to monitor the decreased D-alanine using D-amino acid oxidase mixture (phenol, 4-aminoantipyrine, D-amino acid oxidase, peroxidase). However, the enzyme assay to detect the decreased D-alanine performed far lower sensitivity than to detect the released orthophosphate by adding malachite green reagent.

Usually, for inhibitory compound screening, the persistent enzyme activity was expected. However, during the enzyme activity assay, we found that $T b$-DdlA only could maintain its high activity in 3 days after purification. On the second day, Tb-DdlA remained high activity, the absorbance reached to $0.758 \pm 0.038$ at $620 \mathrm{~nm}$; then the enzyme's activity started to decline and the absorbance of the assay was read as $0.452 \pm 0.099$ at $620 \mathrm{~nm}$ on the third day; until the fourth day, Tb-DdlA lost almost all of its activity $\left(\mathrm{A}_{620 \mathrm{~nm}}\right.$ was about $\left.0.124 \pm 0.002\right)$. For inhibitory compound screening of $\mathrm{Tb}$-DdlA, it was required to prepare the fresh enzyme or improve the storage conditions for $T b$-DdlA. DCS definitely exhibited an inhibitory effect on mycobacteria. Thus, we had perform the DCS inhibitory effect on Msm cells using various final concentrations of DCS containing 0, 5, 10, 25, 50, 100, and $200 \mu \mathrm{g} / \mathrm{mL}$. The results showed that $50 \mu \mathrm{g} / \mathrm{mL}(0.490 \mathrm{mmol} / \mathrm{L})$ of DCS inhibited the cell growth of Msm efficiently in vivo. In this study, the double reciprocal plot indicated that high concentrations of DCS ( $\geq 200 \mu \mathrm{g} / \mathrm{mL})$ displayed inhibitory effects on Tb-DdlA. DCS, a structural analogues of D-alanine, competitively inhibit the bacterial growth by blocking the activity of DdlA and alanine racemase (Alr), theoretically $[17,18]$, and its inhibitory effect depends on the concentration of DCS and D-alanine. In this study, the optimal concentration of D-alanine was determined as $2 \mathrm{mmol} / \mathrm{L}$, so it required high concentrations of DCS $(200 \mu \mathrm{g} / \mathrm{mL}(1.959 \mathrm{mmol} / \mathrm{L}) ; 300 \mu \mathrm{g} / \mathrm{mL}(2.939 \mathrm{mmol} / \mathrm{L}))$ to inhibit $\mathrm{Tb}$-DdlA activity, while less than $100 \mu \mathrm{g} / \mathrm{mL}(0.979 \mathrm{mmol} / \mathrm{L})$ did not display any inhibitory effect on $T b$-DdlA. The double-reciprocal plot also showed that Tb-DdlA exhibited a higher affinity to ATP $\left(\mathrm{K}_{\mathrm{mATP}}: 50.327 \pm 0.465 \mu \mathrm{mol} / \mathrm{L}\right)$ than alanine $\left(\mathrm{K}_{\mathrm{mAla}}: 1.011 \pm 0.094 \mathrm{mmol} / \mathrm{L}\right)$.

The study of protein-protein interactions (PPIs) exhibits crucial roles in the field of medicine, pharmaceutical industry, and biology. Identifying protein interaction sites and uncovering the interaction mechanism is closely relevant in the drug development industry. In addition, unveiling of protein interaction partners allows biologists to construct protein interaction networks, which in turn facilitate the understanding of many biological and clinical observations [19-22]. The data in this study indicated that $T b$-DdlA could not maintain its activity long in vitro under the conditions tested, which might be attributable to its synergistic effect with potential interacting proteins that stabilized its activity in vivo. Therefore, we performed a pull-down assay to identify the interaction partners of $\mathrm{Tb}$-DdlA in $\mathrm{Msm}$. Thus, a Tb-DdlA fusion protein with His-tag was expressed for detecting potential 
interaction partners of $\mathrm{Tb}$-DdlA in $\mathrm{Msm}$ using $\mathrm{Ni}^{2+}$-NTA magnetic agarose beads. In this study, Msm has been used as a surrogate model instead of pathogenic and slower-growing mycobacterial species such as $M t b$ [23]. Msm is a non-pathogenic and fast growing species with highly genetic and antigenic homology with $M t b$ [24]. Msm had similar unique cell wall to Mtb. Additionally, the homology between $T b$-DdlA and its counterpart of Sm-DdlA in Msm had been analyzed. The alignment analysis showed that $\mathrm{Tb}$-DdlA was highly homologous to $S m$-DdlA (the identities accounted for $79 \%$, and the positives accounted for $87 \%$ ). Therefore, it was applicable for pull-down assay to be performed using cell lysates of $\mathrm{Msm}$ as a prey.

Totally, eight different potential interaction partners of $T b$-DdlA had been identified in this study. Among these eight proteins, diaminopimelate decarboxylase (LysA) was of great interests. This enzyme was emphasized because it was particularly important with regard to PG biosynthesis. LysA participates in lysine biosynthesis, and catalyzes the conversion of lysine from meso-2,6-diaminoheptanedioate (DAP) with a liberation of $\mathrm{CO}_{2}$ molecule. DAP metabolic pathway has been attracting considerable attention due to its unique features in prokaryotes and its essentiality to cross-linking of PG which provides strength and rigidity to the cell wall in bacteria. It has been documented that mycobacterial cell walls contained an unusual high content of DAP [13,25-28]. The dipeptide D-alanyl-D-alanine, which catalyzed by DdlA was known to act as a substrate for the synthesis of petapeptides of PG as well. Figure 7 showed that DdlA and LysA had a close relationship in the pathway of PG synthesis. Therefore, we proposed a hypothesis that DdlA and LysA might act synergistically in PG biosynthesis in prokaryotes under the same regulation networks. The D-amino acids, such as DAP and D-alanine, play a crucial role in defining the cellular growth, cell wall integrity and protein synthesis of bacteria. In view of their importance, the designing of potential inhibitory compounds against any enzyme of the regulation networks might display a novel class of antitubercular agents which inhibit bacterial cell wall synthesis and protein biosynthesis, and are not toxic to mammalian species. Interestingly, LuxR family transcriptional regulator and elongation factor Tu were detected as interaction partners of $T b$-DdlA, meanwhile, we performed the pull-down assay for the carboxypeptidase coded by Rv3627c, which hydrolyze the terminal D-alanine from the petapeptides of PG to promote PG crosslink in mycobacteria. The MS identification of Rv3627c interaction partners demonstrated that the above two proteins identified by $T b$-DdlA were detected as interaction partners of Rv3627c, as well (data not published). We hypothesized that the LuxR family transcriptional regulator and elongation factor Tu were involved in the transcription and translation of $\mathrm{Tb}$-DdlA and Rv3627c in mycobacteria, thus, it provided a promising view on anti-mycobacterial drug design that a compound which specifically targets LuxR family transcriptional regulator or elongation factor Tu of prokaryotes may be vital to bacterial survival.

In summary, we developed an easy and fast colorimetric assay for $T b$-DdlA, which could be utilized for high-throughput screening of $T b$-DdlA inhibitory compounds under the reaction conditions determined herein. In addition, we presented an analysis on Tb-DdlA interaction partners by the combination of pull-down assay with MS/MS. Eight putative interaction partners of Tb-DdlA had been identified in this study. Thus, our dataset provided a valuable resource for exploring Tb-DdlA biology. 


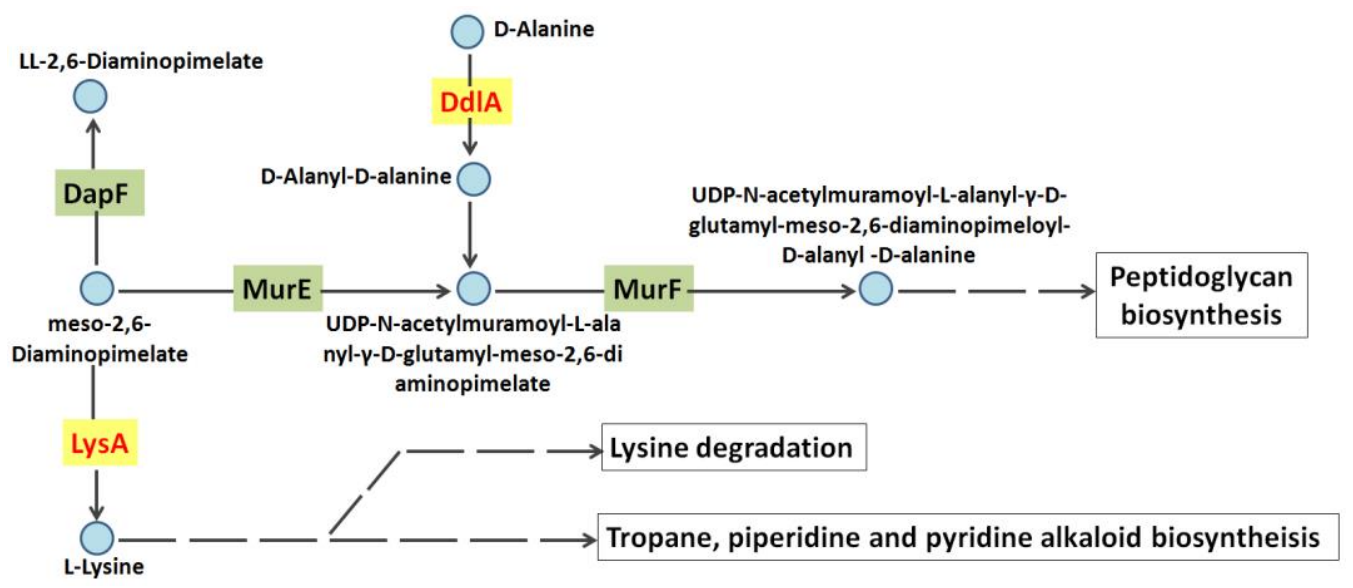

Figure 7. A view of metabolic pathway of DdlA and LysA leading to peptidoglycan biosynthesis. The pathway was summarized from the KEGG website (http:/ / www.kegg.jp/kegg-bin/highlight_ pathway?scale=1.0\&map=mtu00300\&keyword=lysA and http:/ / www.kegg.jp/ kegg-bin/highlight_ pathway?scale $=1.0 \&$ map $=$ mtu01502\&keyword $=\mathrm{ddlA}$ ). Single lines represent the proceeding individual biosynthesis pathway catalyzed by the highlighted gene products. Dashed lines represent a series of successive biosynthesis pathways. Round nodes displayed metabolite intermediates. The genes associated with individual reaction were highlighted in grey color.

\section{Methods}

\subsection{Strains, Plasmids, and Growth Conditions}

The characters of plasmids and bacterial strains used in this context were summarized in Table 3. Escherichia coli NovaBlue and BL21(DE3) cells were grown in Luria-Bertani (LB) broth or LB agar at $37^{\circ} \mathrm{C}$ routinely. $\mathrm{Tb}$-DdlA expression was performed at $16^{\circ} \mathrm{C}$. For the final concentration of antibiotic, $100 \mu \mathrm{g} / \mathrm{mL}$ ampicillin (Amp) was used in this study.

Table 3. Bacterial strains and plasmids used in this study.

\begin{tabular}{|c|c|c|}
\hline Strains/Plasmids & Description & Source \\
\hline \multicolumn{3}{|l|}{ Strains } \\
\hline E. coli NovaBlue & Used for cloning and propagation of plasmids & Novagen \\
\hline E. coli BL21(DE3) & Used for expressing $T b$-DdlA protein & Invitrogen \\
\hline \multicolumn{3}{|l|}{ Plasmids } \\
\hline pMD18-T & Carries $a m p R$ gene; used for cloning PCR product with $\mathrm{A}$ at $3^{\prime}$ ends & Takara \\
\hline pCold II & $\begin{array}{l}\text { Carries ampR gene; contains cold start promoter; used for expressing } \\
\text { M. tuberculosis DdlA }\end{array}$ & Takara \\
\hline pMD18-Tb-ddlA & $\begin{array}{l}\text { Carries ampR gene; } M \text {. tuberculosis ddlA was cloned to the EcoRV site } \\
\text { of pMD18-T }\end{array}$ & This study \\
\hline pCold II-Tb-ddlA & Carries ampR gene; used for expressing $M$. tuberculosis DdlA & This study \\
\hline
\end{tabular}

\subsection{Construction of Tb-ddlA Expression Plasmids}

The Mtb ddlA gene (Rv2981c) was amplified from Mtb H37Rv genomic DNA (supplied by Colorado State University through the NIH contract "Tuberculosis research materials and vaccine testing.") using the forward primer of $5^{\prime}$ AG CATATG AGT GCT AAC GAC CGG CGT G 3" (underlined sequence was NdeI site) and the reverse primer of AT AAGCTT CTA GTG CAG GCC CAC GCC GCG $3^{\prime}$ (underlined sequence was HindIII site). The purified PCR product was cloned into PMD18-T to generate $\mathrm{pMD} 18-\mathrm{Tb}-d d l A$ recombinant plasmid. Then the sequence-confirmed $d d l A$ was cloned into pCold II, which carries a hexahistidine tag and a cold start promoter. The new derived recombinant 
plasmid was named as pCold II-Tb-ddlA, which was transformed into Escherichia coli BL21(DE3) for expression of the fusion protein.

\subsection{Expression, Purification, and Identification of $\mathrm{Tb}-\mathrm{D} d \mathrm{l} A$}

For protein expression, E. coli BL21(DE3) carrying pCold II-Tb ddlA was grown in $200 \mathrm{~mL}$ LB broth containing Amp at $37{ }^{\circ} \mathrm{C}$ until the optical density reached 0.5 at $600 \mathrm{~nm}$, followed by induction with $0.25 \mathrm{mmol} / \mathrm{L}$ isopropyl-D-thiogalactopyranoside (IPTG) at $16{ }^{\circ} \mathrm{C}$ for another 20 $\mathrm{h}$. The cells were harvested and lysed by sonication (30s pulse with $40 \mathrm{~s}$ cooling interval) in chilled lysis buffer $(20 \mathrm{mmol} / \mathrm{L}$ Tris- $\mathrm{HCl}, \mathrm{pH} 8.0,500 \mathrm{mmol} / \mathrm{L} \mathrm{NaCl}, 20 \%$ glycerol, $1 \mathrm{mmol} / \mathrm{L}$ phenylmethylsulphonyl fluoride [PMSF]). Lysates were clarified by centrifugation at $27,000 \times g$ for 40 min, twice. The cytoplasmic fraction was applied to a pre-equilibrated Ni-NTA column (Qiagen) of $1.0 \mathrm{~mL}$ column volume. The column was washed with $20 \mathrm{~mL}$ wash buffer (lysis prep buffer with 20 $\mathrm{mmol} / \mathrm{L}$ imidazole), and eluted with $10 \mathrm{~mL}$ elute buffer (lysis prep buffer with $200 \mathrm{mmol} / \mathrm{L}$ imidazole), $1 \mathrm{~mL}$ was collected for each tube, and the final protein concentration of the elute was determined by BCA kit.

The eluted fractions were analyzed by running a $12 \%$ SDS-polyacrylamide gel in a vertical electrophoresis apparatus and transferred to a nitrocellulose membrane in blotting buffer $(20 \mathrm{mmol} / \mathrm{L}$ Tris-base, $150 \mathrm{mmol} / \mathrm{L}$ glycine and $20 \%$ methanol) to make the proteins accessible to antibody detection. The probing of the membrane with antibody of (anti)-polyhistidine monoclonal HIS-1 (Sigma, St. Louis, MO, USA) was conducted manually followed by incubation with the secondary antibody of antimouse-IgG conjugated alkaline phosphatase (Sigma, St. Louis, MO, USA), and the colorimetric detection of protein bands were developed by BCIP/NBT solution.

\subsection{Functional Assay of Tb-DdlA}

The enzyme's activities were assayed in a 96-well microtiter plate at a total volume of $50 \mu \mathrm{L}$ at $37^{\circ} \mathrm{C}$ for $60 \mathrm{~min}$. The reaction mixture was composed of $100 \mathrm{mmol} / \mathrm{L}$ HEPES (pH 8.0, $100 \mathrm{mmol} / \mathrm{L}$ $\left.\mathrm{KCl}, 100 \mathrm{mmol} / \mathrm{L} \mathrm{MgCl}_{2}, 100 \mu \mathrm{mol} / \mathrm{L} \mathrm{ATP}\right)$, and $2 \mathrm{mmol} / \mathrm{L}$ D-Ala. The purified Tb-DdlA $(20 \mu \mathrm{g} / \mathrm{mL}$ or $10 \mu \mathrm{g} / \mathrm{mL}$ ) was added to start the reaction after all assay components except the $T b$-DdlA were pre-incubated at $37^{\circ} \mathrm{C}$ for $10 \mathrm{~min}$. The enzyme activities were monitored by measuring the release of orthophosphate. The concentration of released orthophosphate was measured by adding malachite green reagent $(0.03 \%(w / v)$ malachite green, $0.2 \%(w / v)$ ammonium molybdate, and $0.05 \%(v / v)$ Triton $\mathrm{X}-100$ in $0.7 \mathrm{~N} \mathrm{HCl}$ ) at $37^{\circ} \mathrm{C}$ for $5 \mathrm{~min}$. The plates were read at $620 \mathrm{~nm}$ by a microplate reader (Thermo Scientific Multiskan Ascent, Thermo Fisher Scientific Oy FI., Vantaa, Finland).

\subsection{Kinetic Analysis of Tb-DdlA}

The steady-state kinetic parameters were routinely evaluated by measuring the release of orthophosphate in microtiter plate. The optimized assay was performed in a final volume of 50 $\mu \mathrm{L}$, and the absorbance was measured at $620 \mathrm{~nm}$. The initial velocity was obtained by performing the enzymatic reaction at different incubation times and different concentrations of the purified enzyme. Then, kinetic parameters of $T b$-DdlA catalyzed reaction were determined in the range of initial velocity. The optimum $\mathrm{pH}$ was determined using HEPES-NaOH at the $\mathrm{pH}$ of 7.2, 7.5, 8.0, and 8.3. The thermal stabilities of $\mathrm{Tb}$-DdlA were determined by measuring enzyme activities at $4{ }^{\circ} \mathrm{C}, 30^{\circ} \mathrm{C}$, $37^{\circ} \mathrm{C}, 42{ }^{\circ} \mathrm{C}$, and $55^{\circ} \mathrm{C}$ in the HEPES-NaOH buffer (pH 8.0). The Michaelis constant $\left(\mathrm{K}_{\mathrm{m}}\right)$ and maximal reaction velocity $\left(\mathrm{V}_{\mathrm{m}}\right)$ were determined by linear regression analysis based on the Lineweaver-Burk equation. The $\mathrm{K}_{\mathrm{mD}-\mathrm{Ala}}$ and $\mathrm{V}_{\mathrm{mD} \text {-Ala }}$ against D-alanine was determined by carrying out the enzymatic reaction at various D-alanine concentrations including $0,0.05,0.1,0.25,0.5,1,2.5$, and $5 \mathrm{mmol} / \mathrm{L}$, and $\mathrm{K}_{\mathrm{mATP}}$ and $\mathrm{V}_{\mathrm{mATP}}$ against ATP was determined by performing the enzymatic reaction at various ATP concentrations containing $0,5,10,25,50,100,200,400,500$, and $1000 \mu \mathrm{mol} / \mathrm{L}$. In this study, each of enzymatic reactions was conducted in triplicate. To eliminate the interference of buffer components, 
the background absorbance of the reaction mixture without $T b$-DdlA was measured and subtracted from the absorbance values with $T b$-DdlA.

\subsection{Colorimetric Inhibition Assay of $\mathrm{Tb}-\mathrm{DdlA}$ by DCS}

The antibiotic DCS, a known substrate competitive inhibitor of $T b$-DdlA, was used to measure the inhibitory effects on $T b$-DdlA protein. A double reciprocal plot was performed in the presence of inhibitor $(0,25,50,100,200$, and $300 \mu \mathrm{g} / \mathrm{mL})$ under the following conditions using $100 \mathrm{mM}$ HEPES ( $\mathrm{pH}$ 8.0, $100 \mathrm{mmol} / \mathrm{L} \mathrm{KCl}, 100 \mathrm{mmol} / \mathrm{L} \mathrm{MgCl} 2,100 \mu \mathrm{mol} / \mathrm{L}$ ATP and a series of gradient concentrations of D-Ala including $0,0.05,0.1,0.25,0.5,1,2.5,5 \mathrm{mmol} / \mathrm{L})$, and $0.25 \mu \mathrm{g}(5 \mu \mathrm{L})$ purified $T b$-DdlA in a total volume of $50 \mu \mathrm{L}$ at $37^{\circ} \mathrm{C}$ for $60 \mathrm{~min}$. DdlA activity was monitored by measuring the release of orthophosphate at $620 \mathrm{~nm}$.

\subsection{Pull down Assay of $\mathrm{Tb}-D d l A$}

Three microgram of purified $\mathrm{His}_{6}$-tagged $T b$-DdlA (bait) was bound with Ni-NTA magnetic agarose beads suspension by rotating slowly at $4{ }^{\circ} \mathrm{C}$ for $1 \mathrm{~h}$, then the supernatant was removed by using the magnetic MagRack6 ${ }^{\mathrm{TM}}$ (Qiagen, Hong Kong) to leave only the magnetic beads with bound proteins in a microcentrifuge tube. The bound $T b$-DdlA were incubated with $200 \mu \mathrm{L}$ soluble proteins (prey) from the whole-cell lysates of $M s m$ with gentle rotation at $4{ }^{\circ} \mathrm{C}$ for $1 \mathrm{~h}$. The resins were washed to remove non-specific bound proteins. The bound proteins were eluted and electrophoresed by $12 \%$ SDS-PAGE. Gel bands were excised for a further MS/MS analysis after visualization by silver staining kit (Sigma, St. Louis, MO, USA). The detailed process of pull-down assay was performed as the manufacturer's instructions.

\subsection{MS/MS Analysis}

Silver-stained gel slices were excised into small pieces followed by decolorization in $100 \mathrm{mmol} / \mathrm{L}$ $\mathrm{NH}_{4} \mathrm{HCO}_{3} / 30 \% A C N$ with $\mathrm{K}_{3} \mathrm{Fe}(\mathrm{CN})_{6}$ and $\mathrm{Na}_{2} \mathrm{~S}_{2} \mathrm{O}_{3}$. Then, the digestion of decolorized gel was performed in $100 \mathrm{mmol} / \mathrm{L} \mathrm{NH}_{4} \mathrm{HCO}_{3}$ solution containing $12.5 \mathrm{ng} / \mu \mathrm{L}$ of sequencing-grade trypsin for $20 \mathrm{~h}$ at $37^{\circ} \mathrm{C}$ according to a modified in-gel trypsin digestion procedure. Mass spectrometry was carried out by using a 5800 MALDI-TOF/TOF MS (AB SCIEX, Foster City, CA, USA) and conducted in positive ionization mode and automatic data acquisition mode. The optimal source/gas parameters were set as follows: the instrument contained a Nd:YAG laser; the mass analyzer scan was 800-4000 Da $\mathrm{m} / z$; the ions were accelerated with a voltage of $2 \mathrm{kV}$; the list of peptides of interest meant for the fragmentation analyses was manually defined in the equipment's current settings with $2 \mathrm{kV}$ collision energy and CID off; data were acquired using Mascot 2.2 software (Matrix Science, http:/ / www.matrixscience.com). The obtained MS/MS spectra were searched against the NCBI database.

Acknowledgments: This work was supported by his work was supported by National Natural Science Foundation of China (81272429).

Author Contributions: W.Z. conceived the study, performed the experiments including pull down assay of $\mathrm{Tb}$-DdlA and kinetic analysis of Tb-DdlA, and contributed in writing of the manuscript. S.Y. performed the experiments including the construction of expression vector and the assay of enzyme activities. Y.X. processed and analyzed the data, and provided material support. Y.W. performed the experiments including protein purification. F.R. provided material support. S.L. contributed in editing the manuscript. W.D. provided financial support. Y.M. provided working space and fundamental material support. All authors shared in the responsibility for the final decision to submit it for publication.

Conflicts of Interest: The authors declared that the research was conducted in the absence of any commercial or financial relationships that could be construed as a potential conflict of interest. The research process was handled objectively and no conflict of interest exists. 


\section{References}

1. WHO. gtbr2017 WHO TB report.pdf. Available online: http://www.who.int/tb/publications/global_ report/en/ (accessed on 1 December 2017).

2. Zhang, W.; Jones, V.C.; Scherman, M.S.; Mahapatra, S.; Crick, D.; Bhamidi, S.; Xin, Y.; McNeil, M.R.; $\mathrm{Ma}, \mathrm{Y}$. Expression, essentiality, and a microtiter plate assay for mycobacterial GlmU, the bifunctional glucosamine-1-phosphate acetyltransferase and $N$-acetylglucosamine-1-phosphate uridyltransferase. Int. J. Biochem. Cell Biol. 2008, 40, 2560-2571. [CrossRef] [PubMed]

3. Ba Diallo, A.; Ossoga, G.W.; Daneau, G.; Lo, S.; Ngandolo, R.; Djaibe, C.D.; Djouater, B.; Mboup, S.; de Jong, B.C.; Diallo, A.G.; et al. Emergence and clonal transmission of multi-drug-resistant tuberculosis among patients in Chad. BMC Infect. Dis. 2017, 17, 579. [CrossRef] [PubMed]

4. Prosser, G.A.; de Carvalho, L.P. Metabolomics Reveal D-alanine: D-Alanine Ligase As the Target of d-Cycloserine in Mycobacterium tuberculosis. ACS Med. Chem. Lett. 2013, 4, 1233-1237. [CrossRef] [PubMed]

5. McCoy, A.J.; Maurelli, A.T. Characterization of Chlamydia MurC-Ddl, a fusion protein exhibiting D-alanyl-D-alanine ligase activity involved in peptidoglycan synthesis and D-cycloserine sensitivity. Mol. Microbiol. 2005, 57, 41-52. [CrossRef] [PubMed]

6. Halouska, S.; Fenton, R.J.; Zinniel, D.K.; Marshall, D.D.; Barletta, R.G.; Powers, R. Metabolomics analysis identifies D-alanine-D-alanine ligase as the primary lethal target of D-Cycloserine in mycobacteria. J. Proteom. Res. 2014, 13, 1065-1076. [CrossRef] [PubMed]

7. Kitamura, Y.; Ebihara, A.; Agari, Y.; Shinkai, A.; Hirotsu, K.; Kuramitsu, S. Structure of D-alanine-D-alanine ligase from Thermus thermophilus HB8: Cumulative conformational change and enzyme-ligand interactions. Acta Crystallogr. Sec. D Biol. Crystallogr. 2009, 65, 1098-1106. [CrossRef] [PubMed]

8. Bruning, J.B.; Murillo, A.C.; Chacon, O.; Barletta, R.G.; Sacchettini, J.C. Structure of the Mycobacterium tuberculosis D-alanine:D-alanine ligase, a target of the antituberculosis drug D-cycloserine. Antimicrob. Agents Chemother. 2011, 55, 291-301. [CrossRef] [PubMed]

9. Lee, J.H.; Na, Y.; Song, H.E.; Kim, D.; Park, B.H.; Rho, S.H.; Im, Y.J.; Kim, M.K.; Kang, G.B.; Lee, D.S.; et al. Crystal structure of the apo form of D-alanine: D-alanine ligase (Ddl) from Thermus caldophilus: A basis for the substrate-induced conformational changes. Proteins 2006, 64, 1078-1082. [CrossRef] [PubMed]

10. Scheffers, D.J.; Pinho, M.G. Bacterial cell wall synthesis: New insights from localization studies. Microbiol. Molecular Biol. Rev. 2005, 69, 585-607. [CrossRef] [PubMed]

11. Sauvage, E.; Kerff, F.; Terrak, M.; Ayala, J.A.; Charlier, P. The penicillin-binding proteins: Structure and role in peptidoglycan biosynthesis. FEMS Microbiol. Rev. 2008, 32, 234-258. [CrossRef] [PubMed]

12. Macheboeuf, P.; Contreras-Martel, C.; Job, V.; Dideberg, O.; Dessen, A. Penicillin binding proteins: Key players in bacterial cell cycle and drug resistance processes. FEMS Microbiol. Rev. 2006, 30, 673-691. [CrossRef] [PubMed]

13. Pavelka, M.S., Jr.; Jacobs, J.W., Jr. Biosynthesis of diaminopimelate, the precursor of lysine and a component of peptidoglycan, is an essential function of Mycobacterium smegmatis. J. Bacteriol. 1996, 178, 6496-6507. [CrossRef] [PubMed]

14. Chen, J.M.; Uplekar, S.; Gordon, S.V.; Cole, S.T. A point mutation in cycA partially contributes to the D-cycloserine resistance trait of Mycobacterium bovis BCG vaccine strains. PLoS ONE 2012, 7, e43467. [CrossRef] [PubMed]

15. Schade, S.; Paulus, W. D-Cycloserine in Neuropsychiatric Diseases: A Systematic Review. Int. J. Neuropsychopharmacol. 2016, 19, pyv102. [CrossRef] [PubMed]

16. CM, S.; DH, B.; EJ, R. Genes required for mycobacterial growth defined by high density mutagenesis. Mol. Microbiol. 2003, 48, 77-84.

17. Feng, Z.; Barletta, R.G. Roles of Mycobacterium smegmatis D-Alanine:D-Alanine Ligase and D-Alanine Racemase in the Mechanisms of Action of and Resistance to the Peptidoglycan Inhibitor D-Cycloserine. Antimicrob. Agents Chemother. 2003, 47, 283-291. [CrossRef] [PubMed]

18. Halouska, S.; Chacon, O.; Fenton, R.J.; Zinniel, D.K.; Barletta, R.G.; Powers, R. Use of NMR metabolomics to analyze the targets of D-cycloserine in mycobacteria: Role of D-alanine racemase. J. Proteom. Res. 2007, 6, 4608-4614. [CrossRef] [PubMed] 
19. Kumar, R.; Samal, S.K.; Routray, S.; Dash, R.; Dixit, A. Identification of oral cancer related candidate genes by integrating protein-protein interactions, gene ontology, pathway analysis and immunohistochemistry. Sci. Rep. 2017, 7, 2472. [CrossRef] [PubMed]

20. Lampe, J.N. Advances in the Understanding of Protein-Protein Interactions in Drug Metabolizing Enzymes through the Use of Biophysical Techniques. Front. Pharmacol. 2017, 8, 521. [CrossRef] [PubMed]

21. Modell, A.E.; Blosser, S.L.; Arora, P.S. Systematic Targeting of Protein-Protein Interactions. Trends Pharmacol. Sci. 2016, 37, 702-713. [CrossRef] [PubMed]

22. Sedan, Y.; Marcu, O.; Lyskov, S.; Schueler-Furman, O. Peptiderive server: Derive peptide inhibitors from protein-protein interactions. Nucleic Acids Res. 2016, 44, W536-W541. [CrossRef] [PubMed]

23. Agrawal, P.; Miryala, S.; Varshney, U. Use of Mycobacterium smegmatis deficient in ADP-ribosyltransferase as surrogate for Mycobacterium tuberculosis in drug testing and mutation analysis. PLoS ONE 2015, 10, e0122076. [CrossRef] [PubMed]

24. Valente, W.; Pienaar, E.; Fast, A.; Fluitt, A.; Whitney, S.; Fenton, R.; Barletta, R.; Chacon, O.; Viljoen, H. A Kinetic Study of In Vitro Lysis of Mycobacterium smegmatis. Chem. Eng. Sci. 2009, 64, 1944-1952. [CrossRef] [PubMed]

25. Wehrmann, A.; Phillipp, B.; Sahm, H.; Eggeling, L. Different modes of diaminopimelate synthesis and their role in cell wall integrity: A study with Corynebacterium glutamicum. J. Bacteriol. 1998, 180, 3159-3165. [PubMed]

26. McCoy, A.J.; Adams, N.E.; Hudson, A.O.; Gilvarg, C.; Leustek, T.; Maurelli, A.T. L,L-diaminopimelate aminotransferase, a trans-kingdom enzyme shared by Chlamydia and plants for synthesis of diaminopimelate/lysine. Proc. Natl. Acad. Sci. USA 2006, 103, 17909-17914. [CrossRef] [PubMed]

27. Gokulan, K.; Rupp, B.; Pavelka, M.S., Jr.; Jacobs, W.R., Jr.; Sacchettini, J.C. Crystal structure of Mycobacterium tuberculosis diaminopimelate decarboxylase, an essential enzyme in bacterial lysine biosynthesis. J. Biol. Chem. 2003, 278, 18588-18596. [CrossRef] [PubMed]

28. Consaul, S.A.; Wright, L.F.; Mahapatra, S.; Crick, D.C.; Pavelka, M.S., Jr. An unusual mutation results in the replacement of diaminopimelate with lanthionine in the peptidoglycan of a mutant strain of Mycobacterium smegmatis. J. Bacteriol. 2005, 187, 1612-1620. [CrossRef] [PubMed]

Sample Availability: Samples of the pCold II-Tb-ddlAplasmid are available from the authors.

(C) 2018 by the authors. Licensee MDPI, Basel, Switzerland. This article is an open access article distributed under the terms and conditions of the Creative Commons Attribution (CC BY) license (http:/ / creativecommons.org/licenses/by/4.0/). 